(2) Open Access Full Text Article

\title{
A bypass case due to an acute inferior myocardial infarction caused by vascular occlusion of the left subclavian artery and left anterior descending
} artery

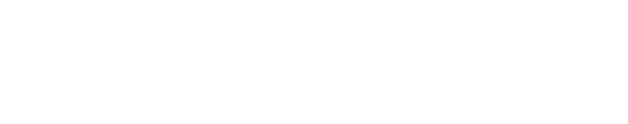

Yakup Altas

Ali Veysel Ulug

Department of Cardiology, Diyarbakir Gazi Yasargil Education and Research Hospital, Diyarbakir, Turkey
Correspondence: Yakup Altas Department of Cardiology, Diyarbakir Gazi Yasargil Education and Research Hospital, Diyarbakir, Turkey Tel +90505 45I 8108 Email drfrtykp@hotmail.com

\begin{abstract}
ST segment elevation is the most common electrocardiographic finding in acute myocardial infarction. ST elevation in chest leads generally represents left anterior descending artery occlusion, while elevation in DII and III, and aVF represents right coronary and circumflex artery occlusion. A female patient aged 66 years was admitted to our emergency service with ST elevation in leads DIII and aVF. A diagnosis of acute inferior myocardial infarction was made. The patient's history included coronary artery bypass graft involving the left internal mammary artery to the left anterior descending coronary artery and aorta to the right coronary artery. The patient was taken to the cardiac catheterization laboratory for primary percutaneous coronary intervention and a lesion in the left anterior descending artery was identified. Additionally, the left subclavian artery was totally occluded. Following intervention to the lesion, the patient was discharged on day 4 of admission.
\end{abstract}

Keywords: electrocardiography, myocardial infarction, coronary circulation

\section{Introduction}

The electrocardiogram (ECG) plays a crucial role in pinpointing the occluded arteries in acute myocardial infarction (MI). ${ }^{1,2}$ However, acute myocarditis, acute pericarditis, the presence of coronary collateral flow, previous infarcts, and differences in the distribution of coronary arteries may affect localization of the responsible coronary artery. ${ }^{3}$ Assessment of the ECG can be complicated in some cases, like electrolyte imbalances, left bundle branch block, paced rhythm, digitalis effects, and early repolarization. In the case presented, emergency coronary angiography was performed due to an acute inferior infarct against a historical background of coronary bypass of the left internal mammary artery to the left anterior descending artery (LIMA-LAD) and aorta to the right coronary artery (Ao-RCA). The unexpected location of the coronary artery obstruction, according to the ECG findings, resulted from complete obstruction of the LAD and the left subclavian artery.

\section{Case report}

Ethical permission was obtained from Gazi Yasargil Education and Research Hospital Ethic Board for this study. The patient provided written informed consent. A 66-yearold female patient with a history of a LIMA-LAD and Ao-RCA coronary artery bypass graft operation performed 19 years ago was admitted to the emergency service with complaints that started 4 hours before her admission. The patient described a 
sensation of chest tightness continuing for $\sim 30$ minutes in cycles, accompanied by sweating. The medical history of the patient revealed hypertension, which had been present for $\sim 20$ years. In addition, she had no history of coronary angiography performed since coronary artery bypass graft. Her regular medications included aspirin, metoprolol, and perindopril. The following findings were observed on the ECG: $1 \mathrm{~mm}$ ST elevation in leads DIII and aVF, $2 \mathrm{~mm}$ ST depression in DI and aVL, and 2-3 $\mathrm{mm}$ ST depression in V2-6 (Figure 1). An acute inferior MI was considered the likely diagnosis, and the patient was admitted to the catheter laboratory for primary percutaneous coronary intervention. Angiography revealed $100 \%$ occlusion of the LAD after the first diagonal, noncritical plaques in the circumflex artery, and $100 \%$ occlusion of the RCA after the sinus branch (Figures 2 and 3). The Ao-RCA graft was 100\% occluded at the proximal (Figure 4). Additionally, the left subclavian artery was $100 \%$ obstructed, as observed during imaging of the LIMA-LAD graft (Figure 5). After evaluation of the patient's angiography findings, the Ao-RCA graft was deemed responsible for the infarction. For this reason, an intervention was attempted on the Ao-RCA graft. However, even after several attempts, the wire could not be advanced further than the $100 \%$ lesion in the proximal aspect. Toward the end of the process, an opaque uptake was observed in the location of the $100 \%$ occlusion, which indicated an acute development of the lesion, therefore an LAD intervention was considered. After the wire was advanced past the lesion, distal flow was established. Afterward, a $2.5 \times 28 \mathrm{~mm}$ drug-eluting stent was placed (Figures 6-8). The collaterals and the distal bed of the RCA were supplied by the LAD in which distal flow was established. After the procedure, the patient's chest pain and ECG findings completely regressed (Figure 9). Fourteen hours after the patient's admission, troponin I levels peaked at $6.6 \mathrm{pg} / \mathrm{mL}$ and then began to decline. In addition, the patient's coronary angiography precoronary artery bypass graft was evaluated, showing an $80 \%$ occlusion of the LAD, which had distal thrombolysis in myocardial infarction grade 3 flow. Echocardiography evaluation on the second day of hospitalization showed $50 \%$ ejection fraction and hypokinesis of the inferoposterolateral wall. No complications occurred during follow-up of the patient. The history of the presenting complaint was not typical of subclavian steal syndrome and angina pectoris. Consultation with the cardiovascular surgery department regarding the left subclavian artery occlusion and a medical follow-up was recommended. LIMA imaging was considered prior to discharge, but was declined by the patient. Aspirin,
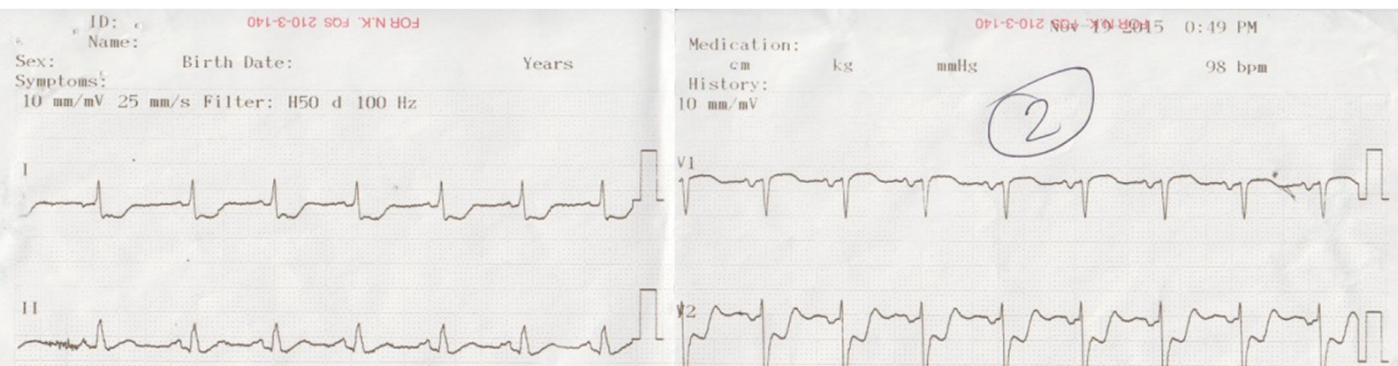

12
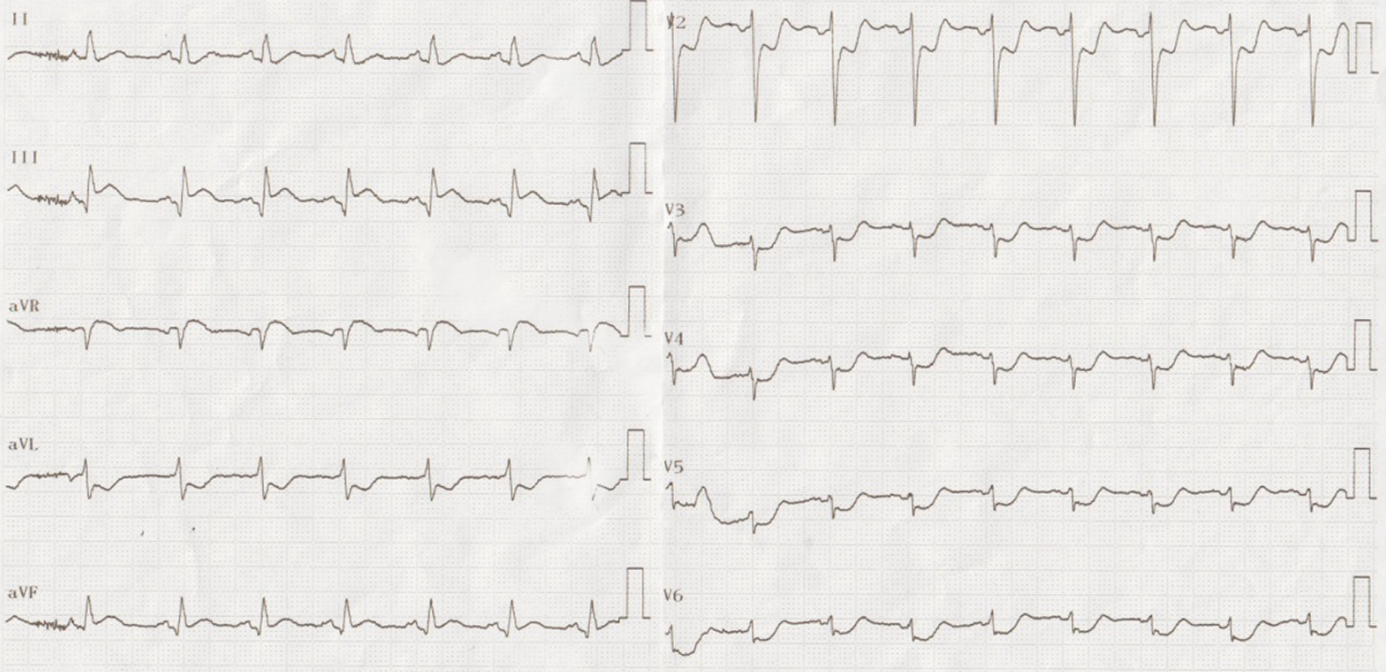

1350k 05-05 03-05 Dept.

(1)

EXam:DIYARBAKIR ÉGITIM 'ARASTIIRMÁ

m

Figure I Electrocardiogram of the patient before intervention. 


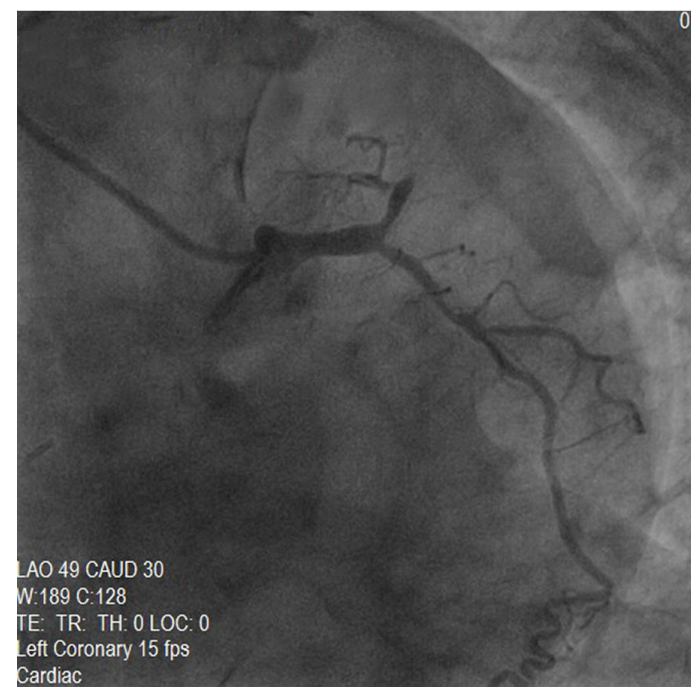

Figure 2 Left anterior oblique (LAO) caudal position of the left coronary arteries. Abbreviation: CAUD, caudal.

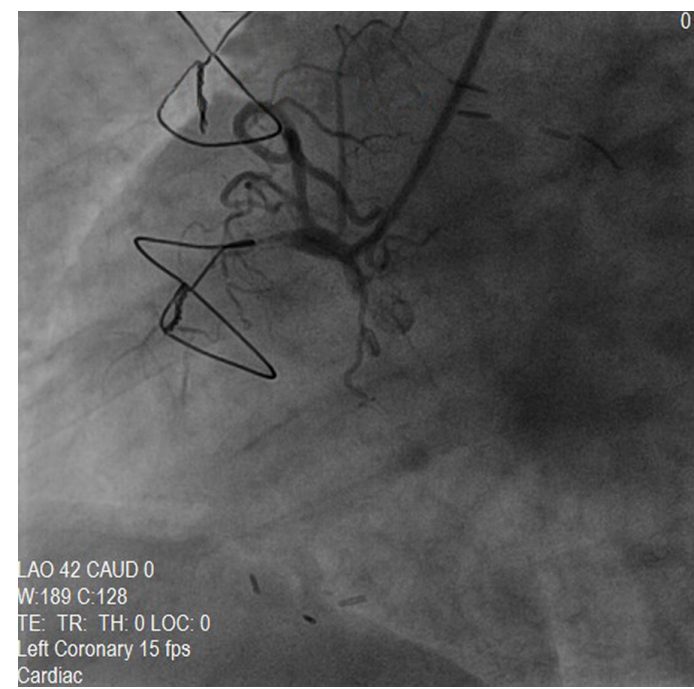

Figure 3 Left anterior oblique (LAO) position of the right coronary artery. Abbreviation: CAUD, caudal.

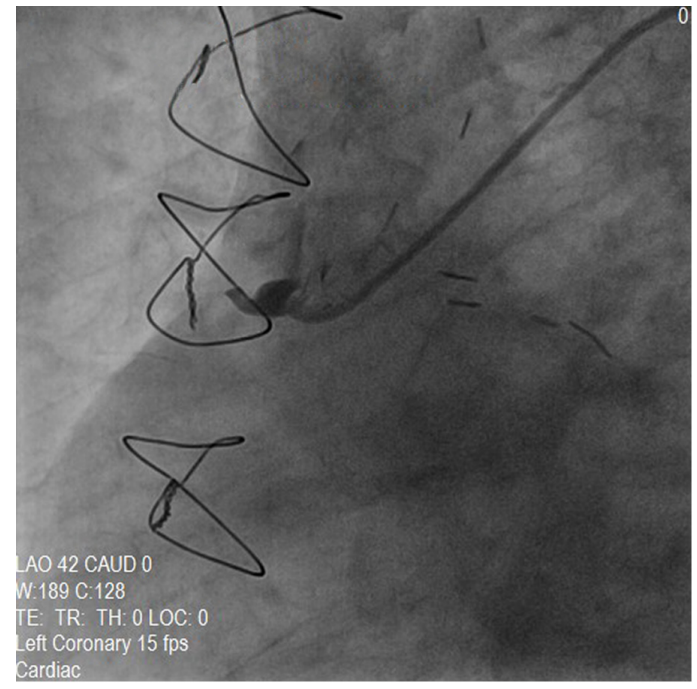

Figure 4 Left anterior oblique (LAO) position of the Ao-RCA graft. Abbreviations: CAUD, caudal; Ao-RCA, aorta to the right coronary artery.

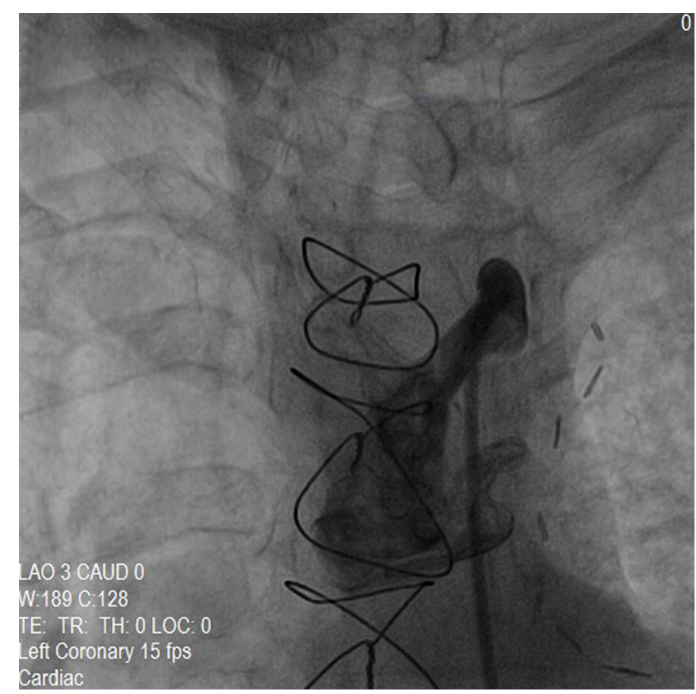

Figure 5 Anterior posterior position of the totally ocluded subclavian artery. Abbreviations: CAUD, caudal; LAO, left anterior oblique.

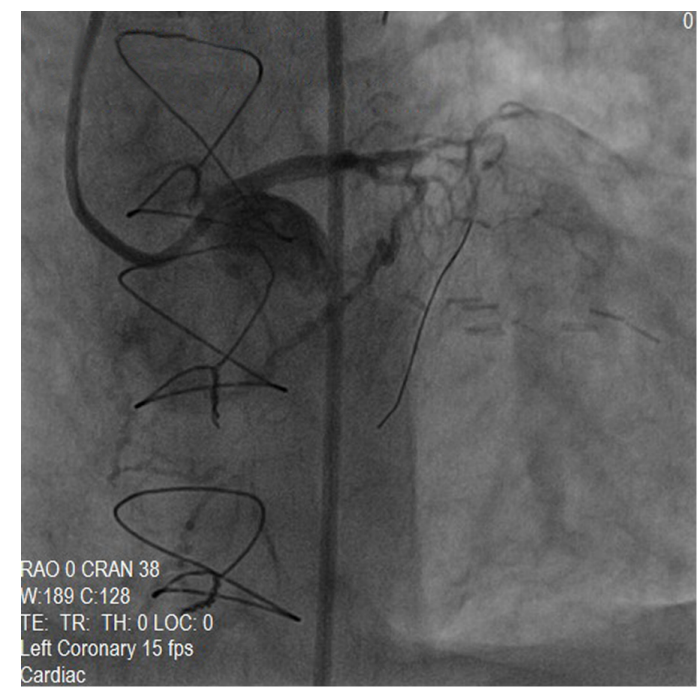

Figure 6 Passing the lesion.

Abbreviations: CRAN, cranial; RAO, right anterior oblique.

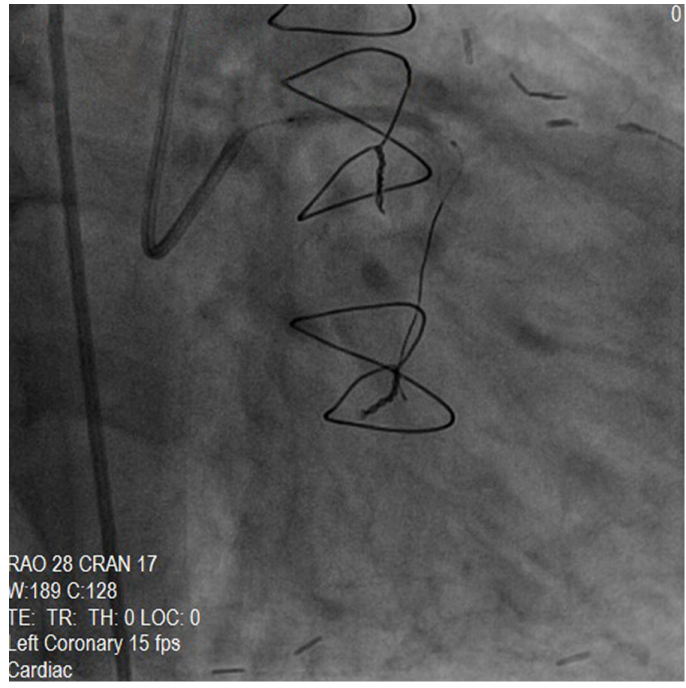

Figure 7 A $2.5 \times 28 \mathrm{~mm}$ drug-eluting stent placement.

Abbreviations: CRAN, cranial; RAO, right anterior oblique. 


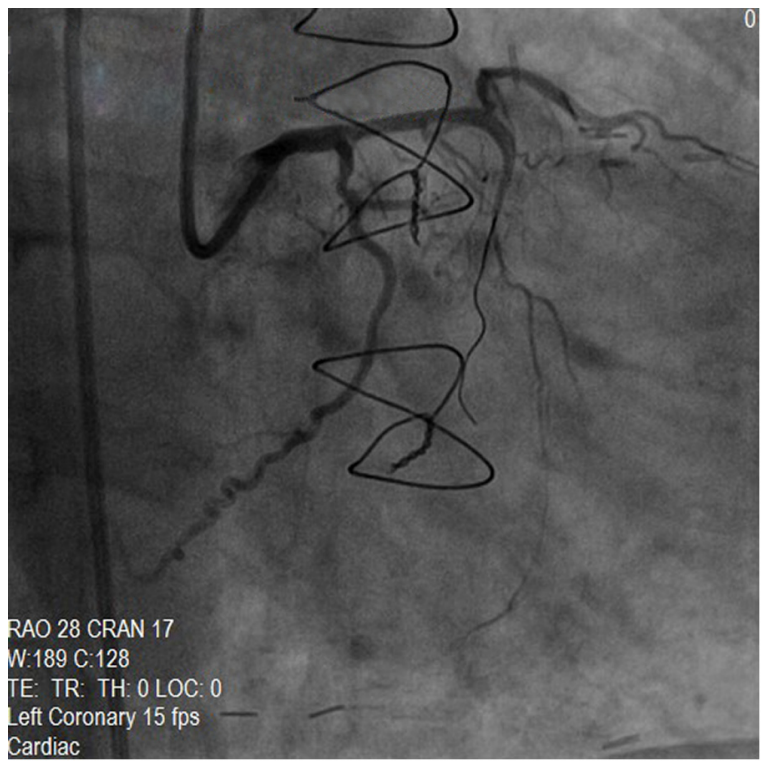

Figure 8 Providing full expansion in left anterior descending artery. Abbreviations: CRAN, cranial; RAO, right anterior oblique.

metoprolol, ticagrelor, rosuvastatin, and perindopril were prescribed for the patient, and she was discharged.

\section{Discussion}

LAD occlusions are responsible for anterior MI. ${ }^{1}$ The higher elevation of lead DIII ST segment in inferior infarcts compared with the elevation of the lead DII ST segment is indicative of an obstruction in the proximal or middle section of the RCA. ${ }^{4}$ The presence of ST elevation in V5-6, together with inferior derivations and the ST segment depression in V2, is indicative of a circumflex obstruction. ${ }^{5}$ The horizontal $\mathrm{ST}$ segment depression in $\mathrm{V} 1-3$, with $\mathrm{R} / \mathrm{S}$ ratio $>1$ and $\mathrm{R}$ $>0.04$ seconds, and the additional presence of an ST segment elevation in V7-8-9 are indicative of a circumflex obstruction and posterior MI. ${ }^{6}$ Even though an ECG can determine the characteristic findings of the LAD and RCA infarction during the acute period of an MI, the accuracy of locating the responsible artery may vary according to the distribution of the coronary artery and the condition of the collateral. ${ }^{7}$ In our case, the following was observed: ST elevation in the inferior leads and V1, and ST depression in the chest leads other than V1. Unexpectedly, the LAD artery was found to be responsible for the infarction. Such cases are rare in the literature. Sapin et $\mathrm{l}^{8}$ presented a study group of 42 cases with LAD occlusion and ST elevation in the inferior leads, which was divided into three subgroups: 1) Distal occlusion of the LAD can cause ischemia, which involves a small anterior area; 2) spreading into the left ventricle/inferior wall of the LAD territory; and 3) presence of collateral flow from the LAD to the inferior wall. ${ }^{8}$ In our case, collateral flow from the LAD distal to the RCA was present. In this respect, our case could be incorporated into the third subgroup. However, the second aspect of our

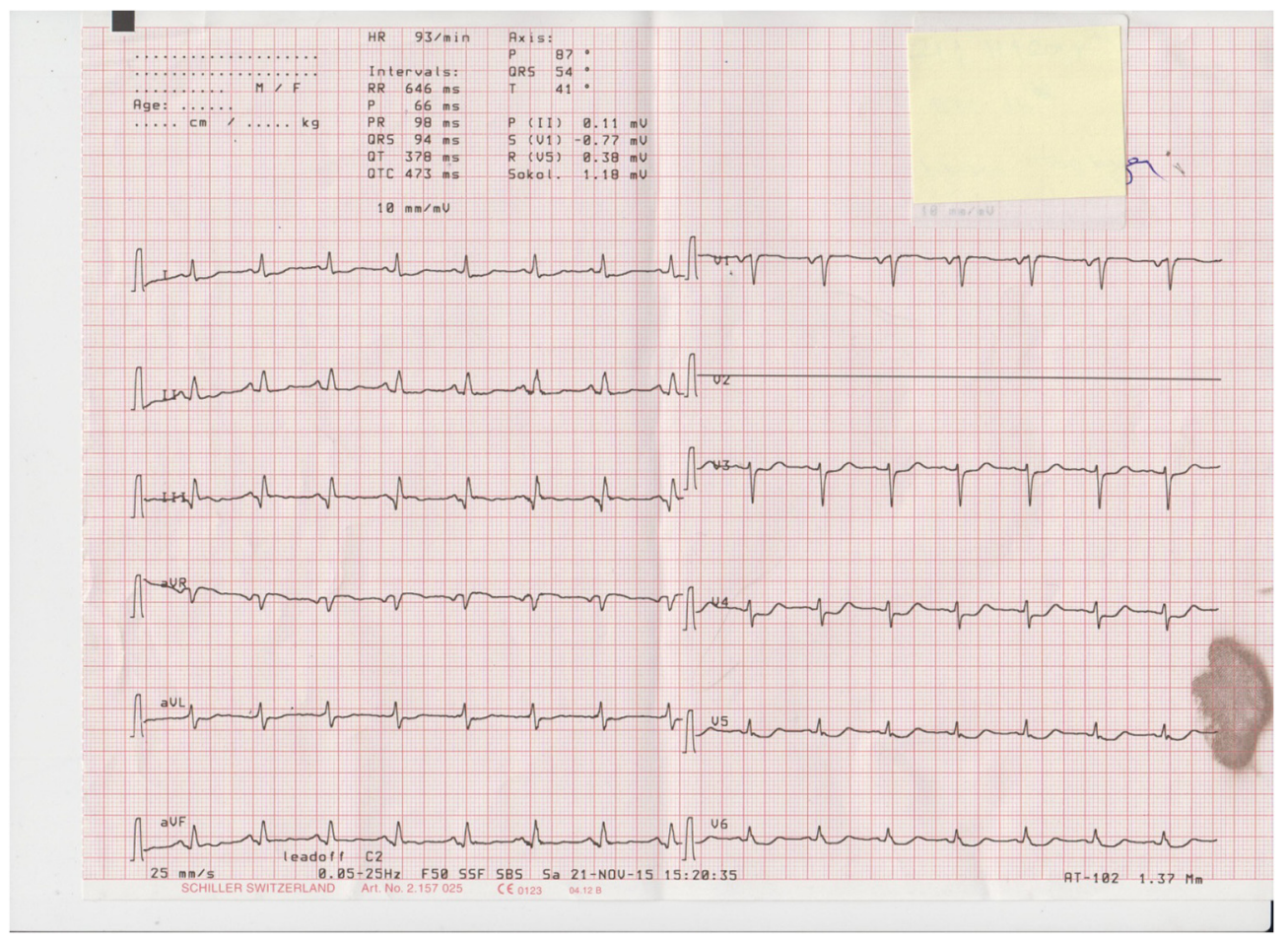

Figure 9 Electrocardiogram findings completely decline. 
patient, which is particularly rare, is her LIMA-LAD and Ao-RCA bypass history and complete obstruction of the left subclavian artery.

\section{Conclusion}

Our case shows that unexpected results can still be observed even if the ECG is a determining factor for the location of the responsible lesion during an acute MI. We would like to create awareness among those who deal with interventional procedures in this regard.

\section{Disclosure}

The authors report no conflicts of interest in this work.

\section{References}

1. Engelen DJ, Gorgels AP, Cheriex EC, et al. Value of the electrocardiogram in localizing the occlusion site in the left anterior descending coronary artery in acute anterior myocardial infarction. J Am Coll Cardiol. 1999;34: 3893-3895.
2. Wellens HJ. The value of the right precordial leads of the electrocardiogram. N Engl J Med. 1999;340:381-383.

3. Antman EM, Braunwald E. Acute Myocardial Infarction. Heart Disease a Textbook of Cardiovascular Medicine. 6th ed. Philadelphia, PA: WB Saunders Company; 2001.

4. Zimetbaum PJ, Krishnan S, Gold A, Carrozza JP, Josephson ME. Usefulness of ST-segment elevation in lead III exceeding that of lead II for identifying the location of the totally occluded coronary artery in inferior wall myocardial infarction. Am J Cardiol. 1998;81:918-919.

5. Kontos MC, Desai PV, Jesse RL, Ornato JP. Usefulness of the admission electrocardiogram for identifying the infarct related artery in inferior wall myocardial infarction. Am J Cardiol. 1997;79:182-184.

6. Kulkarni AU, Brown R, Ayoubi M, Banka VS. Clinical use of posterior electrocardiographic leads: A prospective electrocardiographic analysis during coronary occlusion. Am Heart J. 1996;131:736-741.

7. Porter A, Herz I, Strasberg B. Isolated right ventricular infarction presenting as anterior wall myocardial infarction on electrocardiography. Clin Cardiol. 1997;20:971-973.

8. Sapin PM, Musselman DR, Dehmer GJ, Cascio WE. Implications of inferior ST-segment elevation accompanying anterior wall acute myocardial infarction for the angiographic morphology of the left anterior descending coronary artery morphology and site of occlusion. Am J Cardiol. 1992;69:860-865.
Therapeutics and Clinical Risk Management

\section{Publish your work in this journal}

Therapeutics and Clinical Risk Management is an international, peerreviewed journal of clinical therapeutics and risk management, focusing on concise rapid reporting of clinical studies in all therapeutic areas, outcomes, safety, and programs for the effective, safe, and sustained use of medicines. This journal is indexed on PubMed Central, CAS,

\section{Dovepress}

EMBase, Scopus and the Elsevier Bibliographic databases. The manuscript management system is completely online and includes a very quick and fair peer-review system, which is all easy to use. Visit http://www.dovepress.com/testimonials.php to read real quotes from published authors.

Submit your manuscript here: http://www.dovepress.com/therapeutics-and-clinical-risk-management-journal 